\title{
LA VIRGEN DEL PILAR Y EL ARTE EN EL BRASIL COLONIAL
}

\author{
POR \\ CARlos JaVier CAStro Brunetto \\ Universidad de La Laguna \\ cbrunett@ull.edu.es
}

\begin{abstract}
RESUMEN
En este artículo daremos a conocer un numeroso grupo de imágenes de la Virgen del Pilar que reciben culto en Brasil. Las más antiguas llegaron desde Portugal por la devoción de algunos portugueses que la veneraban en la iglesia de São Vicente de Fora en Lisboa, a finales del siglo XVII. Más adelante la devoción se extendió por Minas Gerais pero, desde el punto de vista artístico, mantuvo siempre la fidelidad iconográfica a la Virgen del Pilar de Zaragoza.
\end{abstract}

PALABRAS CLAVE: Barroco en Brasil; Arte en Brasil; Virgen del Pilar; Virgen del Pilar en Brasil.

\section{OUR LADY OF PILAR AND THE BRAZILIAN COLONIAL ART}

\begin{abstract}
In this article I present a significant amount of images of Our Lady of the Pilar that are venerated in Brazil. The oldest ones arrived from Portugal as a consequence of the devotion of some Portuguese who venerated them in the church of São Vicente de Fora in Lisbon at the end of the XVIIth century. Later on, this devotion extended by Minas Gerais, always maintaining nevertheless the iconographic fidelity from an artistic point of view to Our Lady of Pilar from Zaragoza.
\end{abstract}

KEY WORDS: Baroque in Brazil; Brazilian Art; Our Lady of Pilar; Our Lady of Pilar in Brazil.

$\begin{array}{ll}\text { Recibido/Received } & \text { 27-11-2013 } \\ \text { Aceptado/Accepted } & \text { 04-09-2014 }\end{array}$

\section{LA Virgen del Pilar EN BRASIL}

El primer viaje que realicé a Brasil para familiarizarme con su arte y cultura fue en 1992. Visité Río de Janeiro, Salvador, Vitória (Espírito Santo) y las ciudades históricas de Ouro Preto, Mariana y Sabará en Minas Gerais, conocidas por su producción aurífera. Todas ellas conectaban con el puerto de Paraty, -Estado de Río de Janeiro-, desde donde se transportaban desde comienzos del siglo XVIII, rumbo a la metrópoli, muchas de las riquezas minerales.

Reparé en un hecho singular: la más antigua e importante iglesia de Ouro Preto estaba dedicada a la advocación de Nuestra Señora del Pilar, iconográficamente continuadora de la venerada en Zaragoza. Más tarde, observé que otras localidades de Minas la tenían por patrona o devoción destacada, caso de São João del-Rei y Sabará, hasta llegar a enclaves remotos vinculados a la captura de esclavos y búsqueda de oro, como la villa de Pilar de Goiás. Desde entonces, he apreciado que muchas efigies se encuentran en templos parroquiales, museos y colecciones particulares de la región sudeste-centro brasileño, habiendo desaparecido otras tantas en el Nordeste, justo las más antiguas. A los historiadores locales, familiarizados con su presencia, no les llama la atención y mucho menos he leído reflexiones sobre su iconografía. La pregunta es ¿cómo llegó ese culto e imaginario visual a alcanzar tanto éxito en un sitio extraño a los intereses españoles?

Los estudios sobre la historia de Brasil indican dos fases. La primera se inició hacia mediados del siglo XVI, llegando a su auge a partir de la consolidación de la Unión Ibérica con Felipe II en 1580 y disminuyendo en las primeras décadas del siglo XVII hasta desinflarse tras la Restauración de 1640, con la subida al trono lusitano de D. João IV de Bragança. Durante ese periodo, llamado por la historiografía luso-brasileña como periodo filipino, al margen del comercio oficial, la mayor parte de los españoles que transitaron por las costas del Brasil lo hacían atraídos por el contrabando de mercancías hasta y desde el Río de la Plata, como demuestra Roseli Santaella Stella. ${ }^{1}$

\footnotetext{
1 Stella, R. S. 2000. Brasil durante el gobierno español: 15801640: 67-87. Madrid: Fundación Histórica Tavera.
} 
La segunda fase es posterior a la Unión Ibérica; en realidad, está relacionada con el hallazgo de oro y diamantes en Minas y el control del Río de la Plata. Los esfuerzos diplomáticos bajo el reinado de Fernando VI de España y D. João $\mathrm{V}$ de Portugal por la demarcación de fronteras en América del Sur obtuvieron su fruto con la firma del Tratado de Madrid en 1750 donde, a grandes rasgos, España ganaba la Colonia de Sacramento, que daría origen al Uruguay y a cambio cedía territorios del actual Estado de Rio Grande do Sul y del Amazonas. Esta cuestión, cuyo trasfondo era económico, no incluía la presencia efectiva de españoles en las nuevas regiones de Minas, Goiás o Mato Grosso, sino que se circunscribía al ámbito diplomático. Dicho de otra forma, tras este tratado se esconden intereses políticos, económicos y territoriales, pero no culturales o de encuentros entre españoles y portugueses en regiones como Bahía o Minas. Siendo así, la cuestión que nos ocupa es elucidar cómo la devoción aragonesa se extendió tanto por una tierra sin españoles y con el viento en contra, pues no existe una bibliografía artística de la que partir para abordar este tema. Desde hace veinte años intentamos encontrar una prueba definitiva, la gran respuesta, que satisfaga a historiadores, historiadores del arte, de la vida religiosa, la sociedad; pero mientras los documentos callan, las obras de arte gritan.

Este hecho obliga a que de una vez por todas, se redacte un artículo crítico, éste que ahora presentamos, donde se divulgue la importancia de la Virgen del Pilar para la cultura de Minas. En realidad, los tiempos históricos que analizo, los comienzos del siglo XVIII, son para esa región lo que el periodo visigótico puede representar para el arte español: un periodo donde existen obras de arte a nuestra vista pero del que prácticamente no hay fuentes directas sobre la conformación de su patrimonio, sino vagas referencias de textos secundarios.

Las numerosas imágenes escultóricas brasileñas de esta devoción siguen el esquema de la talla venerada en Zaragoza, esculpida en las primeras décadas del siglo xV y atribuida a Juan de la Huerta. Este elemento añade, aún si cabe, mayor intriga, porque considerando que los escultores que realizaron las tallas brasileñas desconocían la obra original y, en un caso rocambolesco, pudieran haber consultado algún grabado que la reprodujese, ¿cómo es posible tanta cercanía al modelo zaragozano?

\section{EL PROBLEMA DE LAS FUENTES}

La principal dificultad para este estudio se halla en el manejo de fuentes documentales primarias, e incluso impresas, que sean contemporáneas. Es conveniente recordar que los protagonistas de los hechos históricos y de la creación artística vivían en una atmósfera de rudeza donde la presencia de un escribano anotando lo que sucedía representaba más un riesgo que una ayuda, ya que muchos de los actos podrían perjudicar los intereses de la corona. En lo que respecta al entorno eclesiástico, los sacerdotes establecidos en Minas hasta, al menos, la erección de la diócesis de Mariana en 1745 , vivían con bastante libertad y poco gustaban de los libros parroquiales.

A este panorama de escasa preocupación por dejar constancia de lo que acontecía se suma la actitud irrespetuosa con los documentos desde finales del siglo XVIII, cuando los robos de libros e inventarios comenzaron a sucederse en los archivos, pues contenían informaciones sobre intereses económicos particulares. Luego vendrían los hurtos para vender a coleccionistas, principalmente brasileños, norteamericanos y europeos, a lo largo de la primera mitad siglo XX, una práctica extendida que también incluía esculturas, pinturas y joyas. La creación del Instituto do Patrimônio Artístico Nacional por el gobierno federal en 1937 trazó el largo camino conducente a una mejor gestión del patrimonio, así como a la formación de personal especializado, entre ellos, los restauradores. Además, la progresiva organización del Arquivo Público Mineiro, en Belo Horizonte y el esfuerzo eclesiástico en la compilación de documentos en el Arquivo da Cúria de Mariana y de Belo Horizonte, ha conseguido que hoy podamos contar con las fuentes primarias supervivientes que, en muchos casos, estuvieron dispersas y mal conservadas hasta las décadas de 1970 o 1980, en la actualidad al servicio del investigador, pero sabemos que esas fuentes son parciales y no permiten reconstruir de forma secuencial la erección del patrimonio mineiro.

También podemos consultar los fondos del Arquivo Histórico Ultramarino de Lisboa, al preservar documentos generados a instancias del rey para el gobierno de la colonia, y las copias que fueron realizadas por encargo del emperador D. Pedro II del Brasil durante las décadas de 1850 y 1860, a disposición pública en el archivo del Instituto Histórico e Geográfico Brasileiro, en Río de Janeiro. Sin embargo, en ninguno de estos archivos y documentos, consultados exhaustivamente a lo largo de los últimos veinte años, he localizado documentos clarificadores que expliquen la presencia y aumento devocional de la Virgen del Pilar en Brasil, aunque sí informaciones secundarias que son útiles para comprender el contexto en el que nacieron estas imágenes, como ha estudiado para el caso de Bahía Anna Amélia Vieira Nascimento. ${ }^{2}$

Entre los libros impresos, con valor de fuente primaria, se halla Santuário Mariano, escrito por fray Agostinho de Santa María (1648-1728), publicado en diez volúmenes entre 1707 y 1723. Este religioso, perteneciente a la orden de los agustinos descalzos de Portugal, fue nombrado por su erudición secretario de la misma y cronista. Aunque publicó numerosos libros sobre determinadas fundaciones de la orden, dedicó la mayor parte de su empeño en recabar toda la información posible sobre el culto mariano a lo largo y ancho del imperio portugués. ${ }^{3}$ Sea como fuere, la obra constituye la única fuente documental más o menos fiable sobre los comienzos del culto a la Virgen del Pilar y las efigies que la representaron en Brasil.

2 La mencionada investigadora compila todos los documentos conservados en el Arquivo público do Estado da Bahia donde queda expreso de forma manifiesta el poder de dichas Hermandades. No obstante, la mayor parte de los documentos que podemos consultar pertenecen ya al siglo XIX. Sobre una evaluación de estos interesantes fondos, así como sobre el registro de la importancia del culto mariano a través de las fuentes bahianas, consúltese Nascimento, A. A. V. 2000: "As Irmanades na Bahia", en Catálogo das Irmandades, Ordens Terceiras e Confrarias: 1-15. Salvador: SCT/APEB/Fundación Histórica Tavera.

3 Castro, F. L. de [ed.]. 1985. Dicionário cronológico de autores portugueses: 371-372. Mem Martins: Publicações Europa-América. 
Esculturas de la Virgen del Pilar en Bahía, Pernambuco Y RÍO DE JANEIRO

Santa María recoge varias fundaciones a la Virgen del Pilar en Bahía, en las ciudades Salvador y São Francisco do Conde. En el caso de Pernambuco, en su templo de Recife y en la ciudad episcopal de Olinda. Según los testimonios recogidos por fray Agostinho de Santa María, la Virgen del Pilar era invocada como devoción milagrosa en los viajes marítimos y como protectora de las enfermedades y epidemias. En todos los casos deja claro que este culto proviene de su aparición al apóstol Santiago en Zaragoza. Refiriéndose al altar dedicado a esta imagen en la iglesia conocida hoy como Santo Antônio da Barra, en Salvador, entonces llamada Santo Antônio junto à Marina, lo describe de la siguiente manera:

"Nella se vê a Ermita e Santuario de nossa senhora do Pilar, aonde se vê collocada huma milagrosa Imagem desta Senhora. Esta casa he moderna, ainda que não nos constou o anno, em que lhe déu princípio. Fundaraõ e dedicaraõ à Raynha dos Anjos esta casa o Padre Paschoal Duram de Carvalho, João Heytor e Manoel Gomes, todos estes eraõ muyto devotos deste tytulo da Senhora, constalheiaõ as grandes maravilhas que obrava; naõ só em Aragam, mas das que obra na sua cópia que se venera em Lisboa, e a Senhora Ihes inspiraria a fabrica daquella obra, e casa; para que daquelle lugar como de Atalaya, pudesse ella (como quem tudo pode com Seu Santíssimo Filho) livrar dos perigos a todos seus devotos. Edificaraõ esta casa à Senhora tam junto à praya, que o mar está batendo no adro. Feyta e acabada de todo a Ermida, collocáraõ nella a Imagem da Soberana Rainha da Glória, que haviaõ mandado fazer a Lisboa, como se vê em seu altar mór sobre hum trono de serafins. He sua estatura de tres palmos, e tem em seus braços ao Soberano Deos Menino; e he de escultura de madeyra muito bem estofada. Com esta Senhora tem todos os moradores da Bahia muyto grande devoção (...) Tudo isto testemunhaõ os muytos quadros que se vem os enfermos favorecidos do favor e vista daquella benigna Senhora (...)". 4

El contexto son los años finales del siglo XVII y confirma que la Virgen del Pilar era considerada por los bahianos como una protectora de la vida marinera, como baluarte ante tempestades y naufragios, algo inusual en la propia España. Otro testimonio de interés es que justifica su introducción en Salvador da Bahía como una proyección devocional de su culto en Lisboa, en la iglesia de São Vicente de Fora. Sea como fuere, no he podido localizar esa imagen tan antigua, ni se halla en la iglesia de Santo Antônio da Barra, no al menos a la vista pública.

En cuanto a la imagen del Pilar lisboeta, de fecha incierta de comienzos del siglo XVII, según señala Sílvia Ferreira, fue regalada al convento agustino de São Vicente de Fora por el español Baltasar Granero y hecha en Zaragoza, copiando la original de la basílica. La autora no ha conseguido descubrir la data exacta de la llegada de la talla ni su autor, pero sin duda se esculpió a comienzos del siglo XVII, en pleno auge del periodo filipino. Esta devoción lisboeta del Pilar pronto contó con una hermandad formada por nobles, que existió

4 Santa Maria, A. 1722. Santuário Mariano: tomo IX, 61-62. Lisboa Occidental: Officina de António Pedrozo Galram. hasta el siglo XIX. ${ }^{5}$ En cualquier caso, está claramente inspirada en la talla zaragozana y esa semejanza, así como el hecho de mantener un esquema medieval en pleno siglo XVII, es lógica si aceptamos, como apunta José Fernandes Pereira, que en la escultura portuguesa "los artistas y artífices de entonces colocaban su saber al servicio de encargos férreamente definidos y controlados en lo referido al contenido, quedándoles una competencia y especulación de matriz tecnológica". ${ }^{6}$ A nuestro juicio, lo mismo podemos decir de la escultura devocional española.

Fото 1

Nuestra Señora del Pilar. Escultura en madera dorada, anónimo portugués de la primera mitad del siglo XVII. Iglesia de São Vicente de Fora, Lisboa.

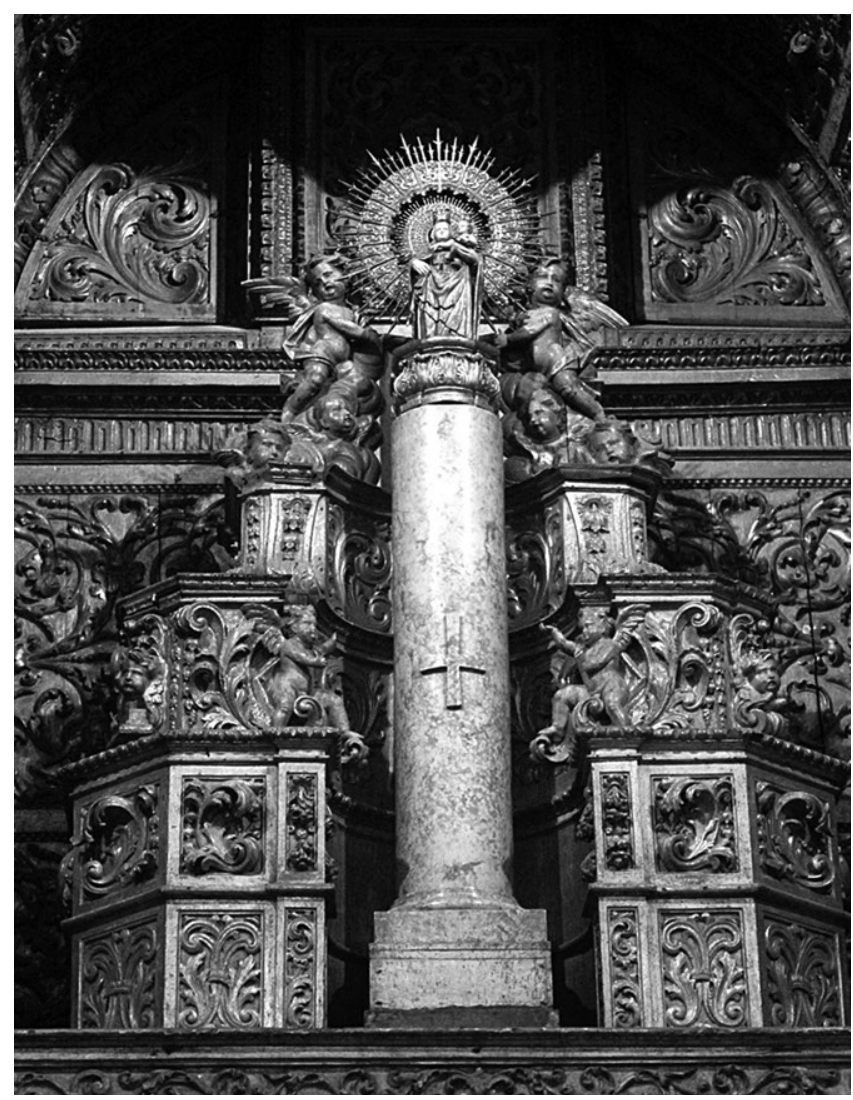

Retornando a Santa María, menciona en Santuário Mariano otra fundación de capilla a la Virgen del Pilar en el siglo XVII, en esta ocasión en la iglesia de São Gonçalo en la villa de São Francisco do Conde, situada en la vecina región conocida como Recôncavo, al norte de la bahía de Todos los Santos. Dice el texto:

“(...) Na mesma igreja parocuial de S. Francisco (...) está esta Santa Imagem, que hé cópia daquella Angelical Imagen, que os Anjos trouxeram do Céo, sobre hum Pilar, e a deraõ por mandado da mesma Senhora, ao Apostolo

5 Ferreira, S. 2010. "A retablística: presença e memória”, en S.C. Saldanha (ed.), Mosteiro de São Vicente de Fora-Arte e História: 289. Lisboa: Centro Cultural/Patriarcado de Lisboa.

6 Pereira, J. F. 1995. "O Barroco do século XVII: transição e mudança”, en P. Pereira (dir.), História da Arte Portuguesa, vol. III: 26. Lisboa: Temas e Debates. 
Santiago, mandarão-na fazer huns seus devotos e a collocaraõ naquella Igreja para nella ser venerada como o mesmo titulo do Pilar; mas hoje não lembra quem elles fossem, nem o ano em que o fizerão (...) He formada esta sagrada Imagem de Madeira e de perfeita escultura e primorosamente estofada tem sobre o seu braço esquerdo ao Soberano Salvador do Mundo, e Deos Menino, adornaõ com manto de seda, e coroa de prata, a sua estatura são três palmos e meyo, e a coluna ou pilar quasi da mesma proporção (...)".7

Como en el caso anterior, no se trata de una devoción que por razones locales recibiese el título del Pilar, sino que alude sin titubeos a la aparición de la Virgen al Apóstol. Además, añade un detalle curioso, que el tamaño considerable de la columna sobre el que reposa la imagen es similar a la pieza aragonesa. Digo que es curioso, porque la mayor parte de las tallas realizadas a partir del siglo XVIII en Minas usan un pilar corto y la Virgen se esculpe de buen tamaño, a veces casi natural, perdiéndose la referencia directa al esquema iconográfico aragonés presente en estas primeras tallas de Bahía. Como en el caso anterior, la imagen original no ha sido localizada, aunque no descartamos su existencia, como sucede con las tallas más antiguas de Brasil, que han sido retiradas del culto, destruidas o lo que es peor, robadas.

Retornando a la ciudad de Salvador, la iglesia de Nossa Senhora do Pilar, de gusto arquitectónico tardobarroco de raíz italiana, fue fundada en $1739^{8}$ y la imagen titular nos muestra el modelo que, he anticipado, triunfaría en el siglo XVIII, una escultura de buen tamaño sobre un pequeño pilar. Como es tradicional en el Barroco brasileño, se pintó la cubierta de madera que cubre el buque del templo, en este caso por el bahiano José Teófilo de Jesús (1758-1847) en 1837, pero con una particularidad iconográfica. En un tondo de forma oval preside la composición la imagen de la Virgen rodeada de ángeles; sin embargo, la figura no porta al Niño Jesús ni los elementos identificativos de esta advocación; solo lleva un cetro en la mano derecha, lo que nos remite a la devoción a la Virgen del Patrocinio, de moda por aquellas fechas en Brasil. ${ }^{9}$ Esta confusión iconográfica suponemos que no se justifica porque el pintor desconociese las fuentes tradicionales, sino por la creación de una nueva imagen de la Virgen del Pilar adaptada a la sensibilidad religiosa de su tiempo.

En Pernambuco fueron fundadas otras capillas o templos a la Virgen del Pilar; la iglesia de Recife se creó hacia 1680 por decisión del procurador de la Hacienda Real, João de Rego Barros. El origen del culto nos remite al viaje que lo trajo desde Portugal, pues temió que el barco sufriese un naufragio y prometió a la Virgen que si lo salvaba, fundaría una capilla en su honor en el puerto de llegada, todo un lugar común recogido por los cronistas. Este puerto fue Recife y por la devoción que tenía a la Virgen del Pilar venerada en su capilla del monasterio de los cônegos regrantes de Santo Agostinho de Lisboa, es decir, el monasterio de São Vicente de Fora, decidió que llevase el título "del

\footnotetext{
7 Santa Maria, A. 1722: 106-107.

8 Bazin, G. 1983. A arquitetura religiosa barroca no Brasil, vol: II, 30-31. Rio de Janeiro: Editora Record.

9 Freire, L. A. R. 2006. A talha neoclássica na Bahia: 291. Rio de Janeiro: Versal.
}

Pilar". Según nos informa Santa María, la imagen se hizo copiando la de Lisboa, con dos palmos y medio de altura, el Niño sobre el brazo izquierdo, sobre un pilar y cubierta con un rico manto. Añade, además, que se convirtió en un gran centro de peregrinación para solicitar milagros y curaciones. ${ }^{10}$ Asimismo, señala que el informante de esta noticia fue el obispo de Pará.

En la vecina ciudad de Olinda también se creó una capilla de la Virgen del Pilar en el templo matriz de San Pedro, bajo la inspiración de la talla lisboeta y con las mismas características formales de la talla de Recife, siendo el fundador el capitán Feliciano de Mello e Sylva. El argumento central de su devoción fue que librase a su familia del contagio de varias epidemias que les cercaban. Según señala Santa María, de todo ello dio cuenta el doctor Pedro Ferreira Brandão, natural de la misma ciudad de Olinda. ${ }^{11}$

Por último, es imprescindible citar el culto a la Virgen del Pilar en una ciudad que conforme avanzaba el siglo XVIII iba cobrando una importancia extraordinaria: Río de Janeiro. En este enclave portuario se asentaron muchos comerciantes y representantes de la hacienda y otras instituciones administrativas. Además, la documentación conservada, en su mayoría, en el Archivo General de Simancas y el Arquivo Histórico Ultramarino de Lisboa, registra lo habitual que era el avituallamiento en el puerto de Río para comerciantes españoles de mercancías lícitas o ilícitas que hacían la ruta hacia el Río de la Plata. De hecho, la parroquia más notoria de Río, la de Nuestra Señora de la Candelaria, responde a una fundación de canarios salvados de un naufragio por lo que fundaron una ermita a la patrona de Canarias. ${ }^{12}$

El culto se estableció en el monasterio benedictino de San Benito. Como indica el historiador del monasterio y monje, Mateus Ramalho Rocha, la existencia de la Hermandad del Pilar dataría hacia $1688 .{ }^{13}$ Esta hermandad, según señalan los libros, conservados solo desde 1734, estaba formada por destacados miembros de la sociedad colonial, es decir, que era una hermandad de blancos, un esquema que venía a reproducir lo que acontecía en la Irmandade de Nossa Senhora do Pilar del monasterio agustino de São Vicente de Fora de Lisboa, formada por nobles de la corte. De este modo, la advocación estuvo siempre relacionada con los grupos privilegiados de la colonia, unidos así a la corte lisboeta, como registran las fuentes impresas, casi las únicas existentes, muy difundidas entre importantes mercaderes lusitanos y altos representantes de la corona en la colonia. Según fray Agostinho de Santa María "Ihe ergiriaõ huma nobre confraria (...) na capela e mais paredes della se vem muitos sinaes das maravilhas que a Senhora tem obrado a favor de seus devotos (...)". ${ }^{14}$

\footnotetext{
$10 \quad$ Santa Maria, A. 1722: 304.

11 Ibídem: 313-314.
}

12 Castro Brunetto, C. J. 2010. ?Los fundadores palmeros de la iglesia de la Candelaria de Río de Janeiro em el arte? Estudios Canarios. Revista del Instituto de Estudios Canarios 54: 73-94.

13 Rocha, M. R. 1992. Iglesia del monasterio de San Benito de Río de Janeiro: 55-56. Rio de Janeiro: Studio HMF/Lúmen Christi.

14 Santa Maria, A. 1723, vol X: 32. 
FOTо 2

Nuestra Señora del Pilar. Escultura en madera dorada y policromada, anónimo brasileño, finales del siglo XVII. Monasterio de São Bento, Río de Janeiro

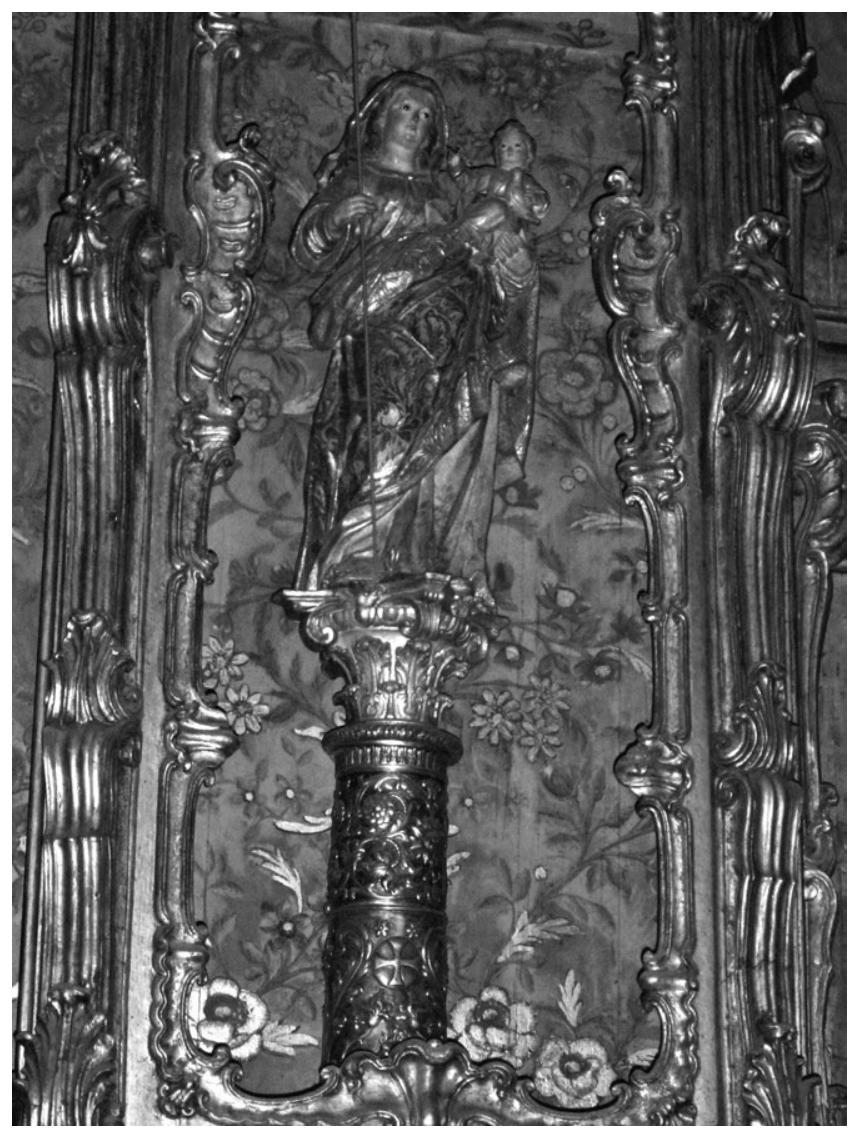

El pilar sobre el que se yergue la imagen está cubierto por un forro de plata labrada, seguramente, durante la primera mitad del siglo XVIII, un periodo durante el cual se realizaron importantes aumentos. ${ }^{15}$ En el primer cuerpo apreciamos la sustitución de la cruz de la Orden de Santiago por la cruz de la Orden de Cristo, cuyo Gran Maestre desde 1551 era el rey de Portugal, y es que esta cruz era entendida como un símbolo de la unión entre el Reino y la Religión en los territorios de ultramar. Esta efigie, que podemos contemplar en su capilla, anuncia la presencia del símbolo lusitano en algunos pilares de templos de Minas Gerais, aunque en la mayor parte de las ocasiones, solo pintada. Por lo demás, presenta la iconografía habitual, con el Niño sobre el brazo izquierdo que sostiene en la mano izquierda, a su vez, al Espíritu Santo en forma de paloma. El brazo derecho de la Virgen porta un objeto, tal vez un cetro, es decir, que no sujeta el manto, como la aragonesa.

Además de este monasterio, en la Baixada Fluminense (Estado de Río de Janeiro), junto al río Iguaçu y en el actual municipio de Duque de Caxias, se levantó otra capilla a la Virgen del Pilar en fecha incierta pero, sin duda, hacia finales del siglo XVII. El lugar fue conocido como Porto do Pilar. En 1725 el proveedor de la hacienda real, Bartholomeu de Cequeira Cordovil, dirigía al rey D. João $\mathrm{V}$ un requerimiento donde:

\footnotetext{
15 Rocha, M. R. 1992: 55.
}

“(...) pedia Ihe mandasse dar de minha fazenda com que se pudesse acabar as obras da dita egreja, attendendo à pobreza daquelles moradores e ao zello em que se tem avido na edificação della (...)". A esto, el rey responde en julio de 1727: "Hei por bem por resolução de 28 de maio deste presente anno, tomada em Conselho Ultramarino, se deem aos effeitos que houver da Fazenda Real mais promptos 250 réis por anno por tempo de quatro annos para a obra do corpo da Egreja da dita Parochia, mostrando-se com effeito se acha acabada a dita capela mór e sacristia, e posta em sua última perfeição (...)". ${ }^{16}$

Lo cierto es que se trataba de un templo junto a un puerto fluvial, cercano al mar, situado en lo que fue una hacienda azucarera colindante con posesiones del monasterio benedictino carioca. ${ }^{17}$ A lo largo del siglo XVIII este puerto fue dedicado al trasporte de riquezas traídas de Minas Gerais y embarcadas con destino a Río de Janeiro. En cualquier caso, de nuevo nos encontramos con el comercio marítimo en el contexto devocional de la Virgen del Pilar. Aunque no hay descripción de la primitiva imagen, hoy desaparecida, nada indica que fuera diferente de la carioca.

Las conclusiones a las que podemos llegar sobre su devoción e imágenes en el litoral entre Pernambuco y Río de Janeiro es que se trata de un culto vinculado, en origen, a la aparición mariana al apóstol Santiago en Zaragoza, pero que llegaría a Brasil a través de la efigie del templo lisboeta de São Vicente de Fora, que fue llevado por comerciantes y autoridades del gobierno colonial. Es decir, que fue una devoción secular y sin vínculos con las órdenes religiosas, incluso en el caso de la capilla en el monasterio benedictino de Río, que era sustentada por una hermandad, no por el clero regular.

\section{LA ViRgen DEL PILAR EN TIERRA DE BANDEIRANTES}

Hablar de Minas Gerais es hablar de la historia más íntima de Brasil. Descubiertas tierras y riquezas auríferas en los años finales del siglo XVII, el impulso de quienes la quisieron dominar provino de aventureros codiciosos, de oficiales del rey cuya prioridad funcionarial era dudosa y de sotanas que servían a Dios mientras se interesaban por el oro que salía de los ríos. Esta afirmación puede parecer severa y generalizadora de actitudes que hoy nos parecen poco éticas e inmorales, pero es que la vida en el Brasil colonial implicaba el encuentro con tierras inhóspitas, indios muchas veces hostiles, calor, mosquitos, serpientes y un horizonte sin fin lleno de incertidumbres y miedo a lo desconocido.

Hacia 1700 la aristocracia lusitana se encontraba en la metrópoli y solo se desplazaban a Brasil quienes recibían encargos de gobierno, fuesen ejecutivos, administrativos o judiciales, lo que privó a la colonia de una nobleza estable. Los comerciantes se establecieron en la costa, principalmente en Recife y Olinda (Pernambuco), en la capital hasta 1763, Salvador da Bahía, en Río de Janeiro, São Paulo, São Vicente y Santos. Los clérigos, repartidos en cinco obispados

16 Dá provisão Sua Magestade pela qual manda se dê 250 réis por ano por tempo de quatro para a obra do corpo da egreja de Nossa Senhora do Pilar de Aguassú, 3 de julio de 1727, Arquivo do Instituto Histórico e Geográfico Brasileiro (IHGB), Arq. 1.2.12, fols. 112v-113v.

17 Araújo, J. de S. P. 1945. Memórias históricas do Rio de Janeiro vol. II, 108. Rio de Janeiro: Imprensa Nacional. 
hasta 1745, reflejaban la situación del Primer Estado de la sociedad moderna; los obispos realizaban pocas visitas a territorios lejanos, la vida religiosa en las urbes estaba a cargo del clero secular y de las órdenes, especialmente franciscanos y benedictinos. Los jesuitas, primeros en evangelizar Brasil, tenían colegios en las ciudades, pero, ante todo, eran misioneros en zonas de fuerte presencia indígena. Entonces, ¿quiénes se adentraron en Minas Gerais?

Para comenzar, hemos de detenernos en el nombre: Minas Gerais, es decir, minas generales, desde el más apreciado de los metales, el oro, abundante en los lechos de los ríos mineiros, hasta los diamantes, el hierro y todo lo que producía en aquel entonces deseos de posesión y promesas de riqueza. La historiografía sobre los orígenes del poblamiento de Minas es amplísima y citarla está fuera de lugar. Sin embargo, Boris Fausto, en un texto que nos aproxima a la historia brasileña de forma sencilla, plantea el hecho comprobado de que los descubridores del inmenso valor económico de las tierras de Minas fueron paulistas de baja condición social y altas ambiciones. ${ }^{18}$ La ciudad de São Paulo, fundada por el jesuita tinerfeño José de Anchieta (1534-1597) y otros miembros de la Compañía, en 1554, se halla situada a unos $90 \mathrm{~km}$ del puerto de Santos y fue punto de partida para la evangelización de los indígenas tupi del interior del sudeste brasileño. Durante el siglo XVII, además de cumplir la función de nexo entre el mundo indígena y occidental, se transformó en un territorio crucial para el desarrollo agropecuario y proporcionó un futuro a los miles de portugueses que, poco a poco, fueron estableciéndose en los márgenes de los ríos Tietê y Paraíba do Sul, y más al norte, del río Paraná.

Los paulistas, deseosos de conocer y explotar nuevas tierras, conocedores a través de los indígenas de la existencia de oro en dirección nordeste, organizaron desde las últimas décadas del siglo XVII lo que se denominaron bandeiras, es decir, grupos de "abanderados" o exploradores que de una forma más o menos organizada, siguieron los márgenes de esos y otros ríos en busca del apreciado oro, que encontraron con la abundancia suficiente como para animar la organización de futuras cabalgadas. Estas expediciones eran integradas también por numerosos esclavos indígenas, y además de la búsqueda de oro, pretendían obtener nuevos esclavos para trabajar en los yacimientos y vetas de metales y piedras preciosas. Según lo establecido por los historiadores brasileños, la penetración en Minas se iniciaría de forma definitiva hacia 1695 y serían sus adelantados Fernão Dias, Borba Gato, su yerno, conocido como el "cazador de esmeraldas", Bartolomeu Bueno de Siqueira o Salvador Fernandes Furtado de Mendonça. Todos estos bandeirantes, hombres rudos singularizados por la búsqueda exclusiva de riqueza, indígenas para esclavizar y oro, fueron los que dieron fundamento a Minas Gerais.

Los paulistas, organizadores de las bandeiras exploradoras y luego explotadoras, querían la posesión y dominio de las tierras descubiertas en esas regiones, pero la corona, rápidamente, comenzó a enviar portugueses desde la corte, conocidos como reinóis y portugueses nacidos en Brasil con mayoritario origen bahiano, a participar de la búsqueda,

18 Fausto, B. 2006. História concisa do Brasil: 53-55. São Paulo: Editora do Estado de São Paulo. pero, sobre todo, con la incumbencia de controlar el oro hallado, cuya quinta parte debía ir a los cofres del Reino. El conflicto no se hizo esperar y el primer hecho significativo de la historia mineira fue la llamada Guerra dos Emboabas entre 1708 y 1709, una auténtica guerra civil entre paulistas y lo que ellos llamaban "extranjeros" que se saldó con la imposición de los deseos de la corona, pero se creó en 1709, como efecto de la capitulación, la Capitania de São Paulo e das Minas de Ouro. La independencia de Minas Gerais como capitanía independiente no llegaría hasta 1720.

La documentación, que mayoritariamente se conserva en el Arquivo Histórico Ultramarino de Portugal, así como copias en varios archivos brasileños, aumentan en número y riqueza informativa conforme avanza el siglo XVIII; pero las fuentes secundarias, como las publicaciones impresas durante ese siglo, entre ellas la literatura épica que se apoya en los bandeirantes para crear un imaginario propio brasileño, ofrecen datos dignos de considerar por los historiadores, sobre todo por los historiadores de la religión y del arte, pues buena parte de la pintura de historia decimonónica se basa en las leyendas de los bandeirantes, como Amador Bueno, Fernão Dias o Bartolomeu Bueno. De hecho, son las que sirvieron luego para construir la iconografía de un Brasil glorioso, primero bajo el imperio de D. Pedro II, y del Brasil republicano desde 1889 . Es el caso de uno de los pintores de historia paulista más conocidos, Oscar Pereira da Silva (1865-1939), quien frecuentaba la biblioteca del Instituto Histórico e Geográfico de São Paulo y el Museu Paulista para conocer la vida y hazañas de los protagonistas de sus futuros cuadros. ${ }^{19}$

Así pues, los orígenes de Minas Gerais están asociados a los bandeirantes, a la esclavitud indígena, a ríos bateados a procura de oro y a yacimientos de diamantes; es decir, que huele a tierra, sudor, sangre y trabajo, un mundo alejado de los caserones y conventos del Brasil costero, donde reproducir la forma de vida de la metrópoli lusitana era un objetivo prioritario. Es lógico que estos hombres toscos no discutiesen sobre formas complejas o simbólicas de representación artística; en el mejor de los casos, pretenderían trasladar al mundo visual los sentimientos espirituales, su fe. Por ello, el primer hecho artístico que caracteriza el arte de Minas Gerais es el sello conservador, pero ¿conservaría formas barrocas?

Cualquier libro de arte publicado en Brasil o que analice el arte de Minas afirma, sin ninguna duda, que el arte mineiro del periodo colonial es exclusivamente barroco. Affonso Ávila, historiador que con un impetuoso celo defendió la originalidad del Barroco de Minas como una imperiosa necesidad para el reconocimiento nacional brasileño, achacaba al siglo XIX una desafección por lo auténtico que representan las formas barrocas. Veía en la actitud extranjerizante de los intelectuales decimonónicos el origen del empobrecimiento cultural del país y el abandono del patrimonio. Fue uno de los impulsores de la revista Barroco, editada por el Centro de Estudos Mineiros desde 1969 y como tal coordinó un libro en 1997 que recogió algunos de los trabajos considerados entonces de mayor impacto. En la presentación del mismo, y valorando la trascendencia del Barroco como identidad, 
señalaba que "se constataba entonces que el estilo y sus múltiples facetas, del mismo modo que se identificaba como raíz de una cultura trasplantada y reducida a la peculiaridad tropical brasileña, las fuentes indican este mismo fenómeno cultural como matrices y respuestas histórico-ideológicas de todo el continente latinoamericano". ${ }^{20}$

Para este historiador, filólogo y filósofo, como para la mayoría de los historiadores del arte que han estudiado Minas, es innegable que el espíritu que revela el imaginario religioso es el propio de la Contrarreforma, y la necesidad de teatralizar los hechos fundamentales de la vida cristiana fue común tanto para las autoridades eclesiásticas como para los frailes, misioneros y creyentes en general. Esto, obviamente, nos conduce desde la Roma pontificia de Bernini hasta las aniñadas Inmaculadas de Murillo. El arte al servicio de la Fe es un elemento de la cultura barroca. Hasta ahí, nada de lo que he señalado es nuevo, pero sí la negación de que, formalmente, la mayor parte del arte mineiro sea barroco, pues la mayoría de las piezas artísticas, sobre todo en lo que a escultura se refiere, revelan una continuidad de las tradiciones flamencas asentadas en la Península Ibérica desde el siglo xV y que tuvieron una notoria expresión en Portugal, generando lo que se ha denominado como arte lusoflamenco.

Las formas llamadas barrocas de Minas durante la primera mitad del siglo XVIII, si conceptualmente se corresponden con esa sensibilidad, formalmente hemos de identificarlas con la influencia gótico flamenca desarrollada en los grandes talleres lusitanos de los siglos xv y XVI, llegados a la colonia en fechas tardías -los ejemplos más antiguos del arte brasileño quinientista responden a esos modelos- y que por falta de experiencia y familiaridad de los autores locales con la estatuaria grandiosa y afectada, teatral y conmovedora, de los talleres del Barroco italiano o español, tuvo como consecuencia la perpetuación de modelos tardomedievales hasta el siglo XIX. Al fin y al cabo, estas respuestas, transversales en Iberoamérica, son comunes en el arte de las periferias. $Y$ es en este grupo donde debemos incluir el objeto de nuestro estudio, las tallas de la Virgen del Pilar veneradas en Brasil.

La llegada de la devoción del Pilar a Minas Gerais tenía el evidente sello de lo secular. Los bandeirantes paulistas trasladarían su culto y aunque fray Agostinho de Santa María no señala templos dedicados a ella en São Paulo, las artes sí dejaron testimonios, entre ellos dos buenos ejemplos en madera tallada y policromada conservados en el Museu de Arte Sacra de São Paulo, clasificados por João Marino. ${ }^{21} \mathrm{El}$ primero y más antiguo, de finales del siglo XVII, es una talla que fue venerada en Itú, interior de São Paulo, de ejecución ordinaria, pero que revela una inspiración directa en el modelo zaragozano y que por razones de compleja explicación, llegó a manos del anónimo artista que la esculpió. Una restauración cuidadosa podría decirnos si nos hallamos ante una importación lusitana, pero, en cualquier caso, se trata de una pieza popular.

El segundo ejemplo, también en manos particulares, pero procedente de Ubatuba, litoral del Estado de São

20 Ávila, A. 1997. Barroco. Teoria e análise: 11. São Paulo: Editora Perspectiva. Belo Horizonte: Companhia Brasileira e Metalurgia e Mineração.

${ }_{21}$ Marino, J. 1996. Iconografia de Nossa Senhora e dos Santos: 23. São Paulo: Banco Safra-Projeto Cultural.
Paulo, presenta una imagen de talla más cuidada, hacia 1750, donde la imagen de María se limita a portar al Niño, y este, a la Paloma. Tal vez se trate de una obra lusa llegada a Brasil, pero estos detalles son difíciles de contrastar, pues las diferencias entre metrópoli y colonia son muchas veces técnicas, no de estilo o iconografía.

Así pues, los bandeirantes por un lado y por otro la influencia cultural proveniente de los comerciantes y funcionarios de los enclaves privilegiados de la colonia, hicieron coincidir una cultura del litoral con otra de selvas y tierras agrestes. La religiosidad laica y la preferencia por devociones populares marianas no vinculadas con las órdenes, puede estar en la raíz de la elección del Pilar para presidir muchos templos mineiros.

El caso paradigmático es la fundación de la iglesia parroquial de Vila Rica de Ouro Preto, principal centro espiritual y económico de Minas colonial. Al ser tantas las publicaciones sobre la fundación de Ouro Preto, me parece oportuno mencionar a uno de los primeros maestros en la divulgación de su historia. Augusto de Lima Júnior, relaciona el origen de Ouro Preto con personajes burdos que corrían tras noticias sobre la aparición de oro, aunque señala que pocos años después, la ciudad actuaba como reclamo "pelo prestigio do nome que alucinava nos que nêle ouviam falar, nas histórias maravilhosas que corriam mundo de bôca em bôca". ${ }^{22}$ Más tarde, el propio autor reconoce que el mejor texto para acceder a los orígenes del lugar y la devoción al Pilar son las referencias de Santa María en su magna obra Santuário Mariano, citada ya tantas veces. Según el religioso, en 1710 se procedió a fundar la iglesia, con las siguientes palabras:

“(...) e porque hum entre os mais era devotíssimo de nossa senhora, a quem sempre invocava com o titulo do pilar (...) fez que todos unidos na mesma devoção procurassem logo dedicalhe hum templo (...) Acabado o templo, e posto em toda perfeyção, tratárão logo de colocar nelle a Santíssima Imagem da Rainha da Glória. He esta sagrada imagem de escultura de madeyra incorruptível, e se vê com seu Santíssimo Filho (...) sobre o braço esquerdo, e ambas as Imagens estaõ coroadas de ouro. Está a Senhora colocada sobre o seu pilar, no meyo do Altar-mór. A sua altura são tres palmos, e o pilar tem os mesmos, este he fingido de pedra, e a Senhora estofada em ouro. O anno em que se solemnizou esta colocação daquella Soberana Senhora, foy de 1710 em dia de sua gloriossa Assumpção (...)". ${ }^{23}$

Los documentos sobre este templo son ricos en informaciones; en 1725 el Conselho Ultramarino reunido en Lisboa, atiende la solicitud del Provedor da Fazenda Real en Vila Rica, Antônio Borquó del Rio, para que la corona asuma las limosnas que los habitantes y su ayuntamiento no habían podido pagar para la construcción del templo del Pilar y que estaba retrasando las obras " $E$ porque não poderão chegar as ditas esmolas para se pôr em sua última perfeição o dito Templo, que Vossa Magestade ordene que da sua real fazenda se concorra para tudo o que faltar (...)". ${ }^{24}$ Se deduce

22 Lima Júnior, A. de. 1957. Vila Rica de Ouro Preto: 60. Belo Horizonte: Edição do Autor.

23 Santa Maria, 1723. Vol X: 237-238.

24 Carta do Conselho que dá conta do Provedor da Fazenda Real das Minas Antônio Borquó del Rio haver conseguido fazer em Vila Rica uma igreja para que possa servir como catedral, 13 de abril de 1725, IHGB, Arq. 1.1.21, fol. 304. 
que la corona ya tenía previsto entonces crear una diócesis en Minas, decisión que solo se adoptaría en 1745, recayendo en la ciudad de Mariana, no en Vila Rica de Ouro Preto.

Con respecto a esa efigie, hemos localizado algunas tallas en las colecciones de Ouro Preto, pero ninguna parece responder a la original descrita en el documento; la que en la actualidad recibe culto en el altar mayor es ya posterior y ha sido intervenida en varias ocasiones aunque mantiene el esquema tradicional de origen aragonés, con el Niño en el brazo izquierdo que porta al Espíritu Santo en forma de paloma. Ahora bien ¿quién introdujo el culto a la Virgen del Pilar en Minas Gerais?

Habitualmente se señala la posibilidad de que se tratase de algún bandeirante, especialmente Bartolomeu Bueno, o moço, nieto de Amador Bueno llamado "el sevillano", carpintero de ribera de Sevilla llegado a Brasil en la flota de Diego Flores de Valdez y establecido en São Paulo. Sin embargo, el tiempo transcurrido entre la partida de su abuelo de Sevilla y la introducción del culto en Minas, a finales del siglo XVII, hace muy fantasiosa esta opción, así como la de los bandeirantes. Sin embargo, el texto de Santa María señala que fue "uno entre los más" el que decidió la dedicación a la Virgen del Pilar. En 1709 fue creado el primer órgano realmente eficiente de gobierno en Minas, la capitania de São Paulo e das Minas de Ouro, siendo nombrado como gobernador Antônio Albuquerque Coelho de Carvalho (1655-1725), nacido en Lisboa y que, en su calidad de militar, tomó parte en la guerra de sucesión contra España.

Aunque su carácter y servicio estaba muy alejado de defender devociones o cualquier otro asunto relacionado con España, el culto a la Virgen del Pilar era lisboeta y elitista, como elitista era la pertenencia a la hermandad del Pilar de Río de Janeiro, de donde fue nombrado gobernador en 1709, un año antes de recibir el nuevo cargo que le llevó a Vila Rica. Quizás la opción por el culto preferente al título del Pilar fuese indicación de este hombre que, sin duda, era uno entre los más; quién sabe si Santa María quería decir uno de tantos o el principal de todos. Si tengo que quedarme con una opción, prefiero la segunda. Al fin y al cabo, como sucedía en Bahía, la Virgen del Pilar era un culto popular entre los laicos, comerciantes y personas principales de Portugal establecidas en la colonia. Quién sabe si ese apelo devocional a la Virgen del Pilar no fuese otra cosa que la expresión de un deseo de reconocimiento y ascenso social, al ser un culto ligado a la corona y a las élites portuguesas desde el siglo XVII.

El principal documento que revela datos de gran interés sobre este templo mineiro es el Triunfo Eucarístico, la relación del traslado del Santísimo Sacramento desde la iglesia de Nuestra Señora del Rosario hasta Nuestra Señora del Pilar en Vila Rica de Ouro Preto, el 24 de mayo de 1733, redactado por Simão Ferreira Machado y publicado en Lisboa al año siguiente. Es el texto fundacional del arte de Minas, no solo por la riqueza de datos que contiene sobre la magna procesión organizada con ese motivo, sino porque recoge una de las mayores fiestas barrocas organizada en toda la historia del Brasil colonial, que fue calificada por Affonso Ávila como la fiesta que inauguró un "estilo de vida barroco". ${ }^{25} \mathrm{El}$ documento describe con detalle las figuras alegóricas utilizadas

25 Ávila, A. 1967. Resíduos seiscentistas em Minas: 11. Belo Horizonte: Centro de Estudos Mineiros. en la procesión, las imágenes de los santos que desfilaron, el color en las opas de quienes intervinieron en el traslado de las efigies, datos sobre los materiales de cada pieza, etc. Con relación al trono de la Virgen del Pilar señala que:

"No meyo della [se refiere a la Hermandad de la Señora del Pilar] se via a imagem da Senhora, estofada de novo com laborioso primor; com pedras finas embotidas nas mesmas roupas; estas cobertas de ouro até os extremos do pilar. $\mathrm{O}$ andor era coberto de custosas sedas de ouro, e prata com artificiosos lavores, e guarnição de galoes, e franjas de ouro". ${ }^{26}$

Fото 3

Nuestra Señora del Pilar. Relieve en madera dorada, anónimo brasileño hacia 1760. Iglesia de Nossa Senhora do Pilar, Ouro Preto

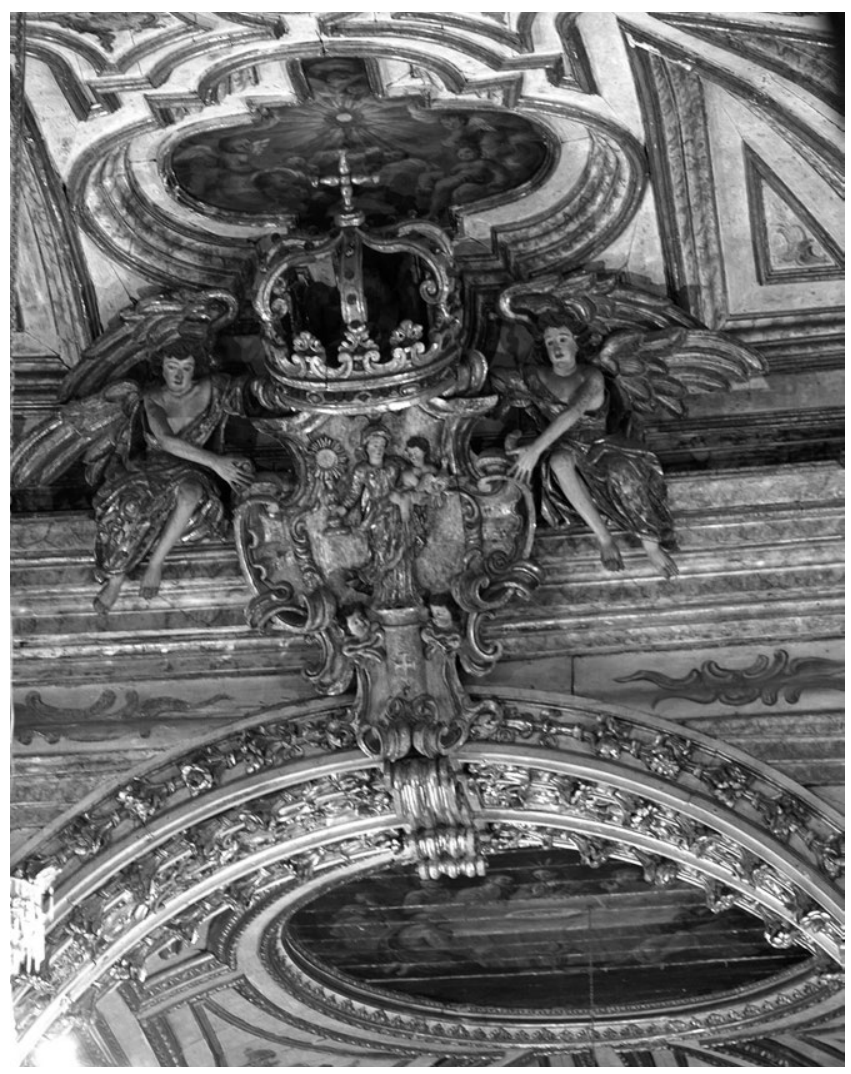

Dadas las limitaciones de espacio que impone un artículo científico, no podemos profundizar más en dicho texto, pero sí apreciar algunos detalles iconográficos; en una de sus páginas, Machado señala que "antes de sahir a procissão, esteve o Divino Sacramento collocado em hum braço da Senhora, em lugar do Menino". ${ }^{27}$ No debe extrañarnos esta curiosa acción piadosa, pues al fin y al cabo, toda la procesión era un acto eucarístico y la trascendencia de esa frase parece insignificante. Sin embargo, el arco toral de la iglesia del Pilar de Ouro Preto está coronado por una gran moldura en talla dorada cuya tarja está presidida por la Virgen del Pilar que sostiene en su brazo izquierdo al Niño, como es habitual, pero

26 Machado, S. F. 1734. Triunfo Eucharístico Exemplar da Christiandade Lusitana em pública exaltação da Fe na solemne Trasladação do Divino Sacramento: 105. Lisboa Occidental: Officina de Música.

27 Ibídem: 46. 
en el derecho porta una gran custodia, lo que es una novedad en esta iconografía mariana. La pieza fue ejecutada con posterioridad a la inauguración del templo, hacia 1760-1770, según se desprende de los estudios de Bazin. ${ }^{28}$ Con toda seguridad su anónimo autor, o quien dictó las formas, se basó en el texto de Machado, publicado varios años antes, como recuerdo permanente de la magna procesión inaugural y del culto al Santísimo Sacramento en el contexto del triunfo de la Contrarreforma. Por último, hemos de indicar que el grabado que cierra este libro incluye una Virgen del Pilar cuyo rasgo más característico, además de mantener la disposición de la talla zaragozana, es la inclusión en el pilar de la cruz de la Orden de Cristo, para hacerla más portuguesa.

Otros ejemplos de gran importancia social y religiosa en Minas son la iglesia parroquial, hoy catedral, de la Virgen del Pilar, en São João del-Rei, en la comarca del Rio das Mortes. La devoción surgió allí, según la tradición histórica y ante la falta de fuentes concluyentes, como consecuencia de la presencia en la zona de bandeirantes, descubridores de nuevos yacimientos. A ellos se atribuye en 1704 la fundación del núcleo poblacional, que alcanzó la categoría de villa en $1713 .{ }^{29} \mathrm{~A}$ partir de ese momento, la devoción creció y hoy encontramos en la catedral varias imágenes de la misma advocación, la más antigua en madera tallada y policromada, continuando el esquema de la zaragozana, y otra de vestir, sobre un pequeño pilar. Ambas pertenecerían a la segunda mitad del siglo XVIII y consolidan la iconografía española, aunque de tradición lusitana.

\section{Fото 4}

Nuestra Señora del Pilar. Escultura en madera dorada y policromada, anónimo brasileño de finales del siglo XVIII. Catedral de Nossa Senhora do Pilar, São João del-Rei

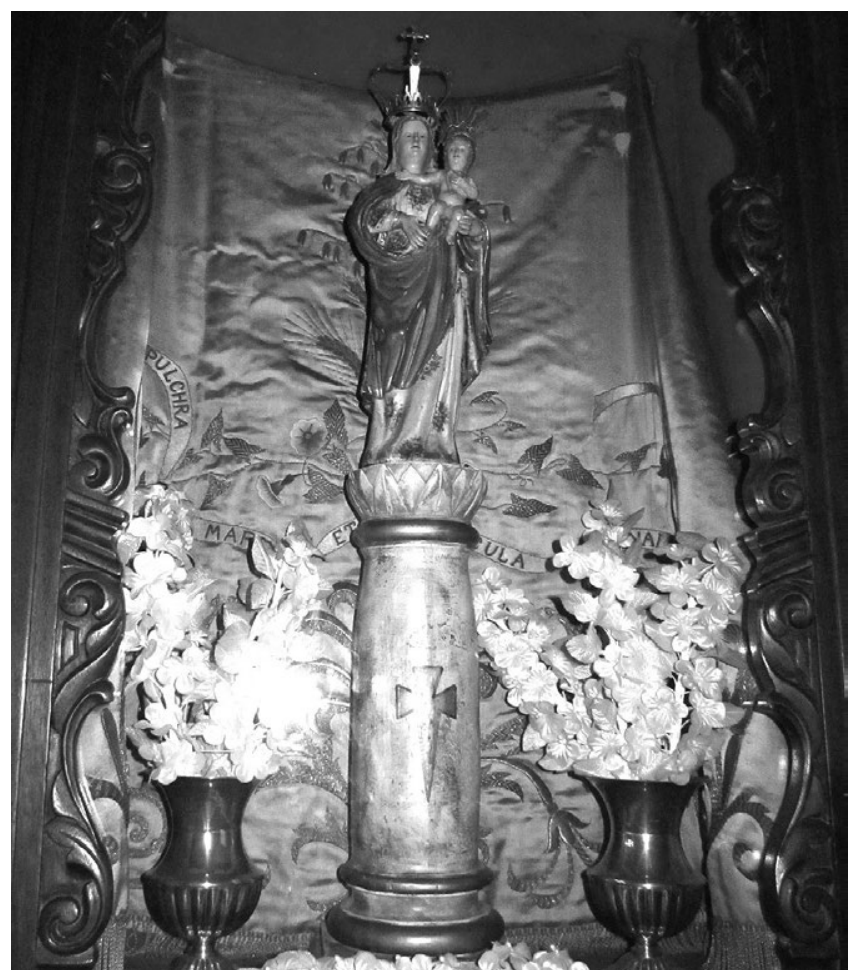

28 Bazin, G. 1983: vol. II, 80-81.

29 Lima, S. J. F de S. 1995. "Arquitetura São-Joanense do século XVIII ao XX". Revista do Instituto Histórico e Geográfico de São João delRei 8: 47-48.
Una de las localidades más antiguas de Minas, Sabará, relacionada con el primer ciclo del oro hacia 1700, cuenta con una capilla del Pilar fundada por el Hospicio de Tierra Santa hacia 1750; desconocemos las razones que justifican este hecho, ni por qué la elección de la Virgen del Pilar; Affonso Ávila ha estudiado la documentación sobre la capiIla, sin apreciar datos certeros, ${ }^{30}$ pero lo cierto es que esta fundación refuerza la hipótesis de ser una devoción esencialmente popular.

Otra capilla de notoria importancia, la de Nossa Senhora do Pilar de Goiás, en el Estado del mismo nombre, adentra su culto en los límites de la Amazonia. En este caso, el aventurero João de Godói Pinto descubrió oro en 1741 y según informa el clérigo e historiador José de Souza Azevedo Pizarro e Araújo (1753-1830), natural de Río de Janeiro y autor de las Memórias históricas do Rio de Janeiro publicadas en 1820, la capilla fue "dedicada pelo povo a N. Senhora do Pilar" y elevada a parroquia en $1755 .{ }^{31}$ La fortuna ha hecho que se conserve una talla que si bien no es la primera, al menos podemos aproximarla a los últimos años del siglo XVIII. En ella se constatan dos hechos: el primero, que el esquema iconográfico incorpora pocas variaciones, como llevar un cetro en la mano, o que la mirada de la Virgen se dirija hacia el Niño con naturalidad. La segunda, que en las imágenes de Minas Gerais, el pilar disminuye de tamaño para dar la preponderancia a la talla de María.

Fото 5

Nuestra Señora del Pilar. Escultura en madera policromada, anónimo brasileño hacia 1800 . Iglesia de Nossa Senhora do Pilar, Pilar de Goiás.

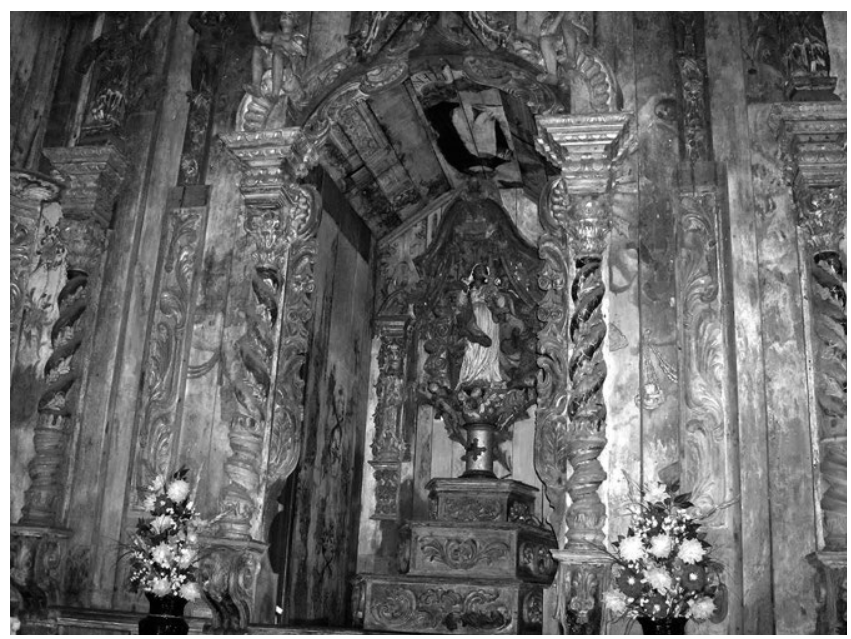

Podría continuar la relación de capillas dedicadas al Pilar, pero, a modo de conclusión, deseo señalar que en Brasil se extendió generosamente el culto a la patrona aragonesa y española, no por la presencia hispana o por personajes significativos que la difundiesen, sino gracias a la relevancia que su culto adquirió en territorio portugués, especialmente en Lisboa, en un ambiente hasta cierto punto elitista. En segundo lugar, que la devoción fue muy popular en la

30 Ávila, A. 1976. "Igrejas e capelas de Sabará". Revista Barroco 8: 40-42.

31 Araújo, J. de S. A. P. 1946. vol. V: 71. 
costa, adoptada por comerciantes y viajeros y en el interior por exploradores y aventureros en busca de oro, además de las autoridades civiles. Tal vez venerar su imagen fuese entonces considerado como un elemento de prestigio, del que ya no tenemos constancia.

Consecuencia de ello es que es el título del Pilar es más laico que cercano a los religiosos regulares y seculares. Por último, que pese al tiempo y la distancia, la iconografía se mantuvo, en general, muy fiel al modelo original. Ello tal vez se deba a que el sello popular fuese un límite para la modificación de los modelos conocidos, o tal vez a que la ausencia de grabados y otras fuentes impidiesen variantes de la imagen, más allá de esculpir más o menos ángeles a los pies del pilar. Lo cierto es que la exclusión de la cruz de Santiago para ser sustituida por la de la Orden de Cristo no fue suficiente para alejarla de lo hispano; el modelo zaragozano siempre se perpetuó. En fin, podemos concluir que en el lejano Brasil colonial las cosas no se regían por patrones de comportamiento lógicos para los europeos; claro que, afortunadamente, tampoco lo hacen hoy.

\section{Bibliografía}

Araújo, J. de S. A. P. 1945-1948. Memórias históricas do Rio de Janeiro, Rio de Janeiro, Imprensa Nacional, 10 vols.

Arquivo Público do Estado da Bahia (Prólogo de A. A. V. Nascimento). 2000. Catálogo das Irmandades e Ordens Terceiras e confrarias. Salvador: SCT/APEB/Fundación Histórica Tavera.

Ávila, A. 1967. Resíduos seiscentistas em Minas. Belo Horizonte: Centro de Estudos Mineiros.

Ávila, A. 1976. "Igrejas e capelas de Sabará”. Revista Barroco 8: 21-65.
Ávila, A. 1997. Barroco. Teoria e análise. São Paulo: Editora Perspectiva, Belo Horizonte, Companhia Brasileira de Metalurgia e Mineração.

Bazin, G. 1983. A arquitetura religiosa barroca no Brasil. Rio de Janeiro: Editora Record, 2 vols.

Castro, F. L. de. 1985. Dicionário cronológico de autores portugueses. Mem Martins: Publicações Europa-América.

Castro Brunetto, C. J. 2010. "Los fundadores palmeros de la iglesia de la Candelaria en Río de Janeiro en el arte". Estudios Canarios: Anuario del Instituto de Estudios Canarios 54: 73-94.

Fausto, B. 2006. História concisa do Brasil. São Paulo: Editora do Estado de São Paulo.

Ferreira, S. 2010. "A retablística: presença e memória”, en S.C. Saldanha (ed.), Mosteiro de São Vicente de Fora-Arte e História: 278-293. Lisboa: Centro Cultural/Patriarcado de Lisboa.

Freire, L. 2006. A talha neoclássica na Bahia. Rio de Janeiro: Versal.

Lima, S. J. F. de S. 1995. "Arquitetura São-Joanense do século XVIII ao XX". Revista do Instituto Histórico e Geográfico de São João del-Rei 8: 47-63.

Lima Júnior, A. de. 1957. Vila Rica de Ouro Preto. Belo Horizonte: Edição do autor.

Machado, S. F. 1734. Triunfo Eucarístico exemplar da Christiandade Lusitana em pública exaltação da Fe na solemne trasladação do Divino Sacramento. Lisboa Occidental: Officina de Música.

Marino, J. 1996. Iconografia de Nossa Senhora e dos santos. São Paulo: Banco Safra-Projeto Cultural.

Pereira, J. F. 1995. "O Barroco do século XVII: transição e mudança", en P. Pereira (dir.), História da Arte Portuguesa. Lisboa: Temas e Debates, vol. III: 11-49.

Rocha, M. R. 1992. Iglesia del monasterio de San Benito de Río de Janeiro. Rio de Janeiro: Studio HMF/ Lúmen Christi.

Santa Maria, F. A. de. 1722. 1723. Santuário Mariano. Lisboa Occidental: Officina de Antônio Pedrozo Galram, vol. IX y vol. X.

Stella, R. S. 2000. Brasil durante el gobierno español: 1580-1640. Madrid: Fundación Histórica Tavera.

Tarasantchi, R. S. 2006. Oscar Pereira da Silva. São Paulo: Empresa das Artes. 